\begin{tabular}{|c|l|}
\hline Title & $\begin{array}{l}\text { Preparation of board-like moldings from composites of isol ated lignins and waste paper II : effect of inorganic salt } \\
\text { addition on board performance and evaluation of practical use of MDF }\end{array}$ \\
\hline Author(s) & Uraki, Y asumitsu; Nemoto, Junji; Y anaga, Kuniy oshi; Koizumi, A kio; Hirai, Takuro \\
\hline Citation & $\begin{array}{l}\text { Journal of Wood Science, 51/6), 589-594 } \\
\text { https://doi.org/10.1007/310086-004-0695-2 }\end{array}$ \\
\hline Issue Date & 2005-12 \\
\hline Doc URL & http://hdl.handle.net/2115/7400 \\
\hline Rights & The original publication is available at www.springerlink.com \\
\hline Type & article (author version) \\
\hline File Information & JWS51_6.pdf \\
\hline
\end{tabular}

Instructions for use 


\title{
Preparation of board-like moldings from Composites of isolated lignins and waste paper II: Effect of inorganic salts addition on board performance and evaluation of practical use of MDF
}

\author{
Yasumitsu Uraki ${ }^{*}$, Junji Nemoto, Kuniyoshi Yanaga, Akio Koizumi, Takuro Hirai \\ Graduate School of Agriculture, Hokkaido University, Sapporo 060-8589, Japan
}

Key words Acetic acid lignin - Waste papers $\cdot$ Lignin adhesive $\cdot$ Hardboard $\cdot$ MDF

Address to which proofs are to be sent

Yasumitsu Uraki, PhD. (*Corresponding author)

Graduate School of Agriculture, Hokkaido Universituy

Kita-9n Nishi-9, Kita-ku, Sapporo 060-8589, Japan

Tel: +81-11-706-2817

Fax: +81-11-716-0879.

E-mail address: $\underline{\text { uraki@for.agr.hokudai.ac.jp }}$ 


\begin{abstract}
Board-shaped composites with medium density (MDF) were prepared from isolated lignins and waste newspaper in addition to preparation of the composites with high density (HB). The board properties of both composites concerning bending strength and water resistance were improved by the addition of hardwood acetic acid lignin (HAL). The internal bond strength and water resistance of MDF, in particular the degree of thickness swelling (TS) were also improved by prolongation of molding time. Adding inorganic salts contributed to the improvement of TS. The effect depended on the positive charge of cation. Considering practical utilization of lignin-based MDF as a structural material, its performance was evaluated by the combination of the single-shear test of nailed joint and the modulus of rigidity. As a result, this MDF had sufficient strength to utilize as an internal shear wall material. Therefore, the lignin can be considered as an alternative to the conventional adhesives for board production such as HB and MDF.
\end{abstract}




\section{INTRODUCTION}

It has been of great importance to effectively utilize biomass, in particular woody biomass that is the most abundant in nature, as an alternative to fossil resources in order to establish a sustainable recycling society with a low load on the environment. Regarding the woody biomass utilization, it is an essential subject to make effective use of lignin, because it has not been utilized efficiently as an organic feedstock except for recovering the energy in paper mills in spite of that lignin is the second abundant component of wood. However, lignin seems to have a high potential as a source for chemicals and synthetic polymers and so on. ${ }^{1}$ From this viewpoint, extensive researches on the lignin utilization mainly as an adhesive or a resin have been reported., ${ }^{2,3}$ Disappointedly, there are only a few industrial products transferred from these basic researches. High production costs per performance in comparison with those of synthetic polymers from petroleum, which are the most serious obstacle to technological transfer, mainly come from the multi-step chemical treatments required for production of lignin-based chemicals. It indicates that lignin should be utilized with no or minimum modification. As an example of lignin utilization without modification, board production using lignin was reported. ${ }^{4}$ When using softwood kraft lignin (KL), thickness swelling was significantly large. This result suggested that KL had low water-repellent ability, and was consistent with previous findings. ${ }^{5}$

Acetic acid lignin (AL) obtained from spent liquor of atmospheric acetic acid pulping has a unique thermal property, that is fusibility. ${ }^{6}$ Technical lignins, such as kraft lignin and lignosulfonate, do not have such property. On the basis of this property, AL could be converted to moldings with various shapes. ${ }^{7,8}$ However, the mechanical strengths of the moldings were very weak because of relatively low molecular mass of AL. ${ }^{6}$ The poor mechanical strengths of the moldings were improved by the addition of cellulosic materials, 
such as viscose rayon and pulps. ${ }^{9}$ This cellulosic fiber-lignin matrix composite is a probable example of direct lignin utilization without any chemical modification.

As the development of this strategy for lignin utilization, we attempted to prepare board-like moldings with a density of $1.4 \mathrm{~g} / \mathrm{cm}^{3}$ from the mixture of AL and waste papers by dry-forming and wet-forming methods in the previous work. ${ }^{5}$ The properties of the moldings were examined according to the standards of fiberboards (FB) from the analogy in constituents. The prepared moldings were categorized into hardboard (HB) (density > 0.8 $\mathrm{g} / \mathrm{cm}^{3}$ ). Both forming types of lignin-based HB fulfilled the Japanese industrial standard (JIS) regulation for $\mathrm{HB}$ of the highest mechanical grade, although the wet-formed boards had relatively superior properties, mechanical strength and water-resistance, to the dry-formed ones. These results suggested that lignin acted more effectively as a hydrophobic adhesive than did KL. The FB from the mixture of lignin and waste papers would bring about an environmentally friendly application of them.

The density $\left(1.4 \mathrm{~g} / \mathrm{cm}^{3}\right)$ of the lignin-based $\mathrm{HB}$ required to obtain satisfactory performance, ${ }^{8}$ however, was too high for handling in construction sites. In this study, we attempt to improve the strength per density of lignin-based HB by adding inorganic salts. This attempt is developed to produce medium density fiberboards (MDF, $0.35<$ density $<0.8 \mathrm{~g} / \mathrm{cm}^{3}$ ) with satisfactory mechanical properties. An expected use of the MDF prepared from the mixture of lignin and waste papers may be a sheet material of wooden shear walls of residential timber constructions. The principal advantage of using this MDF is that they are harmless to human body even when they are used at interior surfaces because of no use of formaldehyde-based adhesive. We attempt to conduct a numerical simulation to estimate the practical potential of the shear walls with this MDF. 


\section{MATERIALS AND METHODS}

\subsection{Materials}

Hardwood acetic acid lignin (HAL) was isolated from the spent liquor of atmospheric acetic acid pulping of birch. ${ }^{9}$ Indulin AT (KL) was used as commercially available kraft lignin. Waste newspaper was used as a fiber component, and designated as WN.

\subsection{Dry-formed HB Preparation}

WN was suspended in water, and then disintegrated by a domestic mixer. After filtration and drying in oven at $105^{\circ} \mathrm{C}$, the $\mathrm{WN}$ was mixed with a given amount of lignin by the mixer. The mixture $(30 \mathrm{~g})$ was placed in a cylindrical mold (diameter, $10 \mathrm{~cm})$, and then molded to a board for 15 min by thermal press under the conditions of the pressure of 3 and $24 \mathrm{MPa}$ and of the temperature of $130^{\circ} \mathrm{C}$. Densities of the resulting moldings were 1.0 and $1.4 \mathrm{~g} / \mathrm{cm}^{3}$, respectively.

\subsection{Dry-formed MDF Preparation}

WN and lignin was suspended together in water, and mixed well by the mixer. After filtration, the mixture was dried at $75^{\circ} \mathrm{C}$ overnight. The moisture content was about $2 \%$. The mixture (HAL 20\%) was molded to a board with the cylindrical mold or the rectangular one $\left(5 \mathrm{X} 20 \mathrm{~cm}\right.$ ) for $30 \mathrm{~min}$ at the pressure of less than $3 \mathrm{MPa}$ and the temperature of $180^{\circ} \mathrm{C}$. The volume of mold or thickness was maintained by controlling the stroke of the press head.

$\mathrm{Al}_{2}\left(\mathrm{SO}_{4}\right)_{3}, \mathrm{CaCl}_{2}$ and $\mathrm{NaCl}$ were added to the aqueous suspension of the WN-HAL mixture. The inorganic salt concentration was $0.3 \%$ on solution. After drying, MDF and HB with $20 \%$ of HAL were prepared by the same procedure as above.

Commercial MDF (type-M: 9 mm-thick for structural use) was used as a reference. Three 
specimens in each board were prepared and subjected to the following tests. However, only one specimen for both the KL-based MDF and the MDF prepared from WN alone was prepared because of shortage of lignin and easy destruction of MDF, respectively.

\subsection{Mechanical Properties and Water Resistance}

The bending modulus of rupture (MOR) and bending modulus of elasticity (MOE) of the prepared rectangular boards were evaluated by the Japanese standard testing method for FB, JIS A 5905. For the circular boards, on the other hand, another testing standard, JIS K 6911 provided for plastics material was adopted because of the restriction of small size of the prepared boards. Internal bond strength (IB) was measured in accordance with JIS A 5905. Water absorption (WA) and the degree of thickness swelling (TS) were calculated from the difference in weight and thickness of specimens between before and after soaking in water for $24 \mathrm{~h}$.

\subsection{Estimation of lateral resistance of wooden shear walls with MDF prepared}

To estimate the practical potential of the dry-formed MDF of HAL20\%-WN, a numerical simulation was conducted on the lateral resistance of the wooden shear walls sheathed with the prepared MDF. Shear walls assembled by nailing sheet materials onto wooden frames are principal structural elements of light timber frame constructions to resist wind or earthquake forces. The lateral resistance of nailed shear walls results from load-slip properties of nailed joints between sheet materials and wooden frames, and in-plane shear rigidity of sheet materials.

The load-slip properties of the nailed joints were evaluated as follows. Two prepared MDF 
pieces of $7.5 \mathrm{~mm}$-thick were nailed onto a softwood lumber with two CN50 common nails, as shown in Fig.1 and relative slip between them was measured throughout the loading. Nailed joints with commercial MDF (type-M: for structural use) of nominal $9 \mathrm{~mm}$-thick and 0.56 $\mathrm{g} / \mathrm{cm}^{3}$ in density were also tested in the same way as the reference. Lumber main-members combined with side-members of prepared and commercial MDF were end matched to each other. The average air-dry density of them was $0.48 \mathrm{~g} / \mathrm{cm}^{3}$. Three specimens consisted of six MDF side members and nails, were tested for each kind of MDF. Moduli of rigidity $(G)$ of both MDF were evaluated by torsional tests.

Lateral load-deformation curves of the nailed shear walls with the prepared or commercial MDF were simulated by incremental analyses, ${ }^{11,12}$ in which we assumed a typical wall with a 3" by 8" (910 x $2440 \mathrm{~mm})$ MDF panel nailed on one side on spacing of less than $100 \mathrm{~mm} .^{13}$ As illustrated in Fig.2, the allowable shear wall resistance was calculated from the simulated load-deformation curve as the minimum value among the following four lateral loads according to the standard evaluation method. ${ }^{12}$ The loads are (1) the yield load (Py), (2) 2/3 of the maximum load $(P \mathrm{~m}),(3)$ the load at the allowable shear strain $1 / 150 \mathrm{rad}$, and (4) $0.2 / D$ s of the maximum load $P$ m where $D$ s is the structural characteristic factor. ${ }^{12}$ The calculated value was modified to the standardized allowable shear wall resistance per unit wall width $1 \mathrm{~m}$.

\section{RESULTS AND DISCUSSIONS}

\subsection{Properties of $H B$}

We have already revealed that $\mathrm{HB}$ with a density of $1.4 \mathrm{~g} / \mathrm{cm}^{3}$ prepared from the composites of HAL and WN by the dry-forming fulfilled the JIS regulation with the highest mechanical grade in the previous report. ${ }^{5}$ When using $15 \%$ HAL, the HB showed the maximum strength that was about three-fold of HB from WN alone. The water-resistance was also improved by 
the addition of HAL. These results suggested that HAL acted as a hydrophobic and hot-melt type of adhesive. However, this board density was higher than that of the conventional HB $\left(<1.0 \mathrm{~g} / \mathrm{cm}^{3}\right)$. For practical use, the density should be decreased. By controlling the molding pressure, a decrease of the density was achieved. The properties, MOR and water-resistance, of the resulting board (HAL 20\%, diameter $10 \mathrm{~cm}$ ) were deteriorated as decreasing board density (Fig. 3).

The improvement of the property of the dry-formed HB was attempted by the addition of inorganic salts as retention-aid agents, which were used for enforcement of bonding between cellulosic fibers in the paper-making. ${ }^{14}$ The MOR of $\mathrm{HB}$ with a density of $1.0 \mathrm{~g} / \mathrm{cm}^{3}$ was significantly increased by the addition of $\mathrm{NaCl}$, while the other salts, $\mathrm{CaCl}_{2}$ and $\mathrm{Al}_{2}\left(\mathrm{SO}_{4}\right)_{3}$ slightly affected (Fig. 4). However, WA and TS that are parameters concerning water-resistance were remarkably improved by the salts addition, and the effect was dependent on the positive charge of cationic ions. The effect of cation on board performance was interpreted as follows. Cation-containing pulp swelled well in the water by osmotic pressure of free cations. ${ }^{14}$ In particular, sodium ion with monovalency has strong effect. When the swollen pulp was subjected to dryness, much larger hydrogen bonding was formed. Therefore, bonding strength between fibers were improved. In addition, multi-valent cations would have contributed to crosslink between pulp with negative zeta potential and relatively anionic lignin by electrostatic interaction to prevent swelling against water. However, the cations have too weak ability of pulp swelling to enhance mechanical strength drastically.

\subsection{Dry-formed $M D F$}

Recently, the production and consumption of MDF markedly increased. Therefore, commercially available MDF should also be produced from the mixture of lignin and waste 
paper. Lowering the molding pressure can produce low-density boards. However, the press machine that was used in this study could not be regulated in a range of low pressure. We prepared MDF with a density of $0.6-0.8 \mathrm{~g} / \mathrm{cm}^{3}$ and a thickness of about $4 \mathrm{~mm}$ (diameter 10 $\mathrm{cm})$ and $7.5 \mathrm{~mm}(5 \times 20 \mathrm{~cm})$ by controlling molding volume, which was carried out by maintaining stroke of press machine in a certain distance. As shown in Fig. 4, the MOR in the density range of MDF was very low, and WA was significantly high. The bending strength fulfilled the minimum criterion of JIS for MDF, but WA should be improved.

In order to improve the board property, molding time was prolonged so that the molten lignin dispersed well into the space between fibers and covered the fibers to give water-resistance, because HAL acted as the hot-melt type of adhesive. The internal bond strength was significantly improved by extending the molding time, although it had not clear effect on MOR, as shown in Fig. 5. These results revealed that it took a long molding time to transmit the heat required to melt and disperse HAL throughout the thickness of a board. Then it significantly affected the internal bond strength, in which the strength of the weakest layer of a board was critical. The MOR, on the other hand, was mainly determined by the strength of the outer layers which could be easily heated. Water-resistance, TS in particular, which was reflected the property throughout the thickness, was also improved. The resultant MOR and TS were a little less than the JIS regulations, MOR $>15 \mathrm{MPa}$ and TS $<12 \%$ for MDF with 7-15 mm-thick.

As well as HB, the effect of inorganic salts on the board property of MDF (density, 0.7 $\mathrm{g} / \mathrm{cm}^{3}$ ) was investigated (Fig. 4). The addition of inorganic salts did not influence on the mechanical strength. However, the TS was unambiguously improved by $\mathrm{Al}_{2}\left(\mathrm{SO}_{4}\right)_{3}$. In MDF regulation of JIS, TS was regarded as a more important parameter than WA. Hence, salts addition positively affected on the MDF property. 
The characteristic of the salt-enforced MDF was compared to that of commercially available MDF, as shown in Table 1. Larger specimens (width, $5 \mathrm{~cm}$; length, $20 \mathrm{~cm}$; thickness, 7.5-9.0 $\mathrm{g} / \mathrm{cm}^{3}$ ) were used in accordance with fiberboard regulation. To investigate the influence of lignin sort, the properties of $\mathrm{Al}_{2}\left(\mathrm{SO}_{4}\right)_{3}$-containing $\mathrm{MDF}$ prepared from the mixture of KL-WN and WN alone were also listed. The MDF prepared merely from WN had a very weak strength and less water-resistance. By the addition of KL, the performance was slightly improved, but was much less than commercial one. The HAL-based MDF showed a little superior IB to the commercial one, but MOR was a half. Thus, HAL was found to be more suitable than KL as adhesive, but the property was not apparently satisfactory.

\subsection{Allowable lateral resistance of the shear walls with MDF prepared}

Fig. 6 shows the averaged load-slip curves of the nailed joints with the prepared and commercial MDF used in the analyses. The averaged moduli of rigidity $(G)$ of the prepared and commercial MDF are $1.09 \mathrm{GPa}$ and $1.95 \mathrm{GPa}$, respectively. Fig. 7 shows the lateral load-deformation curves simulated based on these basic data. From this figure, the average lateral resistance of the shear wall sheathed on one side per unit wall width was evaluated to be $4.91 \mathrm{kN} / \mathrm{m}$ for the prepared MDF and $6.37 \mathrm{kN} / \mathrm{m}$ for the commercial MDF. These values, however, do not give an exact comparison between two kinds of MDF because of the incompatibility in their density and thickness. Though allowable lateral resistance of the shear wall is generally determined as the $50^{\text {th }}$ percentile value with 75 percent confidence of the lateral resistance, it cannot be determined directly here. However, we may be able to roughly estimate it as follows. The shear wall factor given for commercial MDF used in this study is 3.0, which ensures that its lowest allowable lateral resistance is equal or more than $5.88 \mathrm{kN} / \mathrm{m}$. Then, the allowable lateral resistance of the shear walls with prepared MDF is roughly 
estimated as $4.50 \mathrm{kN} / \mathrm{m}$ if the variance of it is not very larger than the variance of the resistance of the walls with commercial MDF. More conservative estimation may give 4.00 $\mathrm{kN} / \mathrm{m}$.

At any rate, the allowable resistance 4.50 or $4.00 \mathrm{kN} / \mathrm{m}$ for the prepared MDF seems practically available. Internal shear walls are usually sheathed on both sides with the same sheet material. Their lateral resistance, then, becomes twice the resistance of shear walls sheathed on one side. The resultant allowable resistance 9.00 or $8.00 \mathrm{kN} / \mathrm{m}$ for the prepared MDF is sufficient for ordinary residential constructions. It is because that the ultimate resistance of timber constructions is determined not only by the lateral resistance of shear walls but also by the resistance of structural joints which must transmit the lateral forces from shear walls to foundations. In most of the practical design of internal shear walls, the expected lateral resistance is usually 6.0 to $8.0 \mathrm{kN} / \mathrm{m}$ even in the regions of strong winds and earthquakes.

When the prepared MDF are used on the internal sides of external shear walls, the external sides of them can be sheathed with stronger sheet materials.

\subsection{Practical potential of the prepared MDF for structural use}

A disadvantage of the prepared MDF is relatively low water resistance. This disadvantage, however, seems not to be serious in actual use of the prepared MDF. The principal advantage of it, harmlessness to human body, must lead it to proper use for internal walls. The material for internal use has less risk of degradation due to high moisture in comparison with the external sheathing materials of external walls or roofs. Relatively inferior bending properties of prepared MDF are not so critical when used for interior walls. Bending properties are important mainly for floor or roof materials, or external sheathing materials of external walls. 
An expected performance of sheathing materials of internal walls may be satisfactory resistance of nailed or screwed joints. For residential constructions in aging society, internal walls at any position of which handrails can be fixed easily with nails or screws are very convenient. Of course, it is better if the sheathing material satisfying this need is harmless to human body and environmental-friendly. The lateral resistance shown in Fig. 6 was practically available.

\section{CONCLUSION}

Isolated lignins and waste paper could be converted to boards, which were considered regenerated wood materials. AL was a suitable source among the lignins for board production because it acted as the hydrophobic and hot-melt type adhesive. ${ }^{5}$ The high-density HB completely fulfilled HB regulation of JIS. Unfortunately, the density of the HB was relatively high. When the density was decreased, the board property was deteriorated. However, this problem was overcome by the addition of inorganic salts and prolongation of molding time. In particular, the water-resistance was remarkably improved.

We prepared MDF in this study. Most of the parameters of the MDF concerning the board properties except for the internal bonding were inferior to those of the commercial MDF. However, from the point of view as constructional material, the MDF had mechanical strength enough for sheet material of internal shear wall.

The FB's, HB and MDF, have an advantage over the traditional FB; the FB's are environmentally friendly boards because of using recycled paper and pulping byproduct without formaldehyde-based adhesive. Accordingly, the FB can be utilized as internal wall that does not pollute the residential atmosphere.

In this study, we showed one example of direct lignin utilization for the board making. The 
molding technique will be applied to produce not only $\mathrm{HB}$ and MDF but also other paper-based materials, for instance paper receptacle. 


\section{REFERENCES}

1. Goldstein IS (1975) Potential for converting wood into plastics. Science 189: 847-852

2. Nimz HH (1983) Lignin-based wood adhesives. In: Pizzi A. (ed) Wood adhesives -chemistry and technology-. Marcel Dekker Inc, New York and Basel, pp 247-288

3.Vázquez G, Rodríguez-Bona C, Freire S, González-Álvarez J, Antorrena G (1999) Acetosolv pine lignin as copolymer in resins for manufacture of exterior grade plywoods. Bioresource Technol 70: 209-214

4. Kawano T. (1998) Board production using Gramineae lignin. Japan Pat. H10-305409.

5. Nemoto J, Uraki Y, Sano Y (2003) Preparation of Board-like Moldings from Composites of Isolated Lignins and Waste Paper. Mokuzai Gakkaishi 49: 287-292

6. Kubo S, Uraki Y, Sano Y (1996) Thermomechanical analysis of isolated lignins. Holzforschung 50: 144-150

7. Uraki Y, Kubo S, Nigo N, Sano Y, Sasaya T (1995) Preparation of carbon fibers from organosolv lignin obtained by aqueous acetic acid pulping. Holzforschung 49: 343-350

8. Uraki Y, Kubo S, Kurakami H, Sano Y (1997) Activated carbon fibers from acetic acid lignin. Holzforschung 51, 188-192. 
9. Uraki Y, Kubo S, Sano Y (2002) Preparation of activated carbon moldings from the mixture of waste newspaper and isolated lignins -Mechanical strength of thin sheet and adsorption property-. J Wood Sci 48: 521-526.

10. Uraki Y, Kubo S, Sano Y, Sasaya T (1991) Cooking of hardwoods with organosolv pulping in aqueous acetic acid containing sulfuric acid at atmospheric pressure. Kami-pa Gikyoshi 45: 1018-1024.

11. Yanaga K, Sasaki Y, Hirai T (2001) Estimation of Allowable Resistance of Nailed Shear Walls Considering the Variance of Nailed Joint Resistance. Mokuzai Gakkaishi 47: 242-251.

12. Yanaga K, Sasaki Y, Hirai T (2002) Estimation of Shear Resistance of Nailed Shear Walls Considering Vertical Loads and Pull-up Resistance of Stud-Bottom Plate Joints. Mokuzai Gakkaishi 48: 152-159

13. The Editorial Committee of the Guide for Structural Design of Light Timber Frame Construction (ed) (2002). In: The guide for structural design of light timber frame construction. Japan 2 X 4 Home Builders Association pp 214-216

14. Scallan AM, Grignon J (1979) The effect of cations on pulp and paper properties. Svensk Papperstidn 82, 40-47. 


\section{Figure captions}

Fig. 1. An experimental illustration of single-shear test of nailed joint.

Fig. 2. A typical load-deformation curve for determination of allowable resistance.

Note: Pm: Maximum lateral road. Py: Yield load defined at the intersection of line $a$ and $c . K$ :

Initial modulus defined at slope of the line $d$. Line a links $0.1 P \mathrm{~m}$ and $0.4 P \mathrm{~m}$ on the curve.

Line $b$ links $0.4 P \mathrm{~m}$ and $0.9 P \mathrm{~m}$ on the curve. Line $c$ is the tangent parallel to line $b$. Line $d$ links the origin and the yield point on the curve that is transferred parallel to the horizontal axis from the intersection of line $a$ and $c$.

Fig. 3. Modulus of rupture (MOR, - ) and water absorption (WA, $\bigcirc$ ) of the boards as a function of their density. The molding temperature and time were $180^{\circ} \mathrm{C}$ and $15 \mathrm{~min}$, respectively. The bar revealed the range between maximum and minimum values in three specimens tested.

Fig. 4. Effect of inorganic salt on MOR, WA and thickness swelling (TS) of the boards with density of 1.0 and $0.7 \mathrm{~g} / \mathrm{cm} 3$. The molding temperature and time were $180^{\circ} \mathrm{C}$ and $15 \mathrm{~min}$, respectively. The bar revealed the range between maximum and minimum values in three specimens tested.

Fig. 5. Effect of molding time on MOR, IB, WA and TS of the boards. The molding temperature was $180^{\circ} \mathrm{C}$ and the board density was $0.7 \mathrm{~g} / \mathrm{cm} 3$.

Fig. 6. Averaged load-slip curves of the nailed joint in single shear tests. 
Fig. 7. Simulated load-deformation curves of the nailed shear wall. 
Table 1. Properties of medium density fiberboard (MDF).

\begin{tabular}{|c|c|c|c|c|c|c|c|}
\hline MDF type* & $\begin{array}{c}\text { Thickness } \\
(\mathrm{mm})\end{array}$ & $\begin{array}{l}\text { Density } \\
\left(\mathrm{g} / \mathrm{cm}^{3}\right)\end{array}$ & $\begin{array}{l}\text { MOR } \\
(\mathrm{MPa})\end{array}$ & $\begin{array}{l}\text { MOE } \\
(\mathrm{GPa})\end{array}$ & $\begin{array}{c}\mathrm{IB} \\
(\mathrm{MPa})\end{array}$ & $\begin{array}{l}\text { WA } \\
(\%)\end{array}$ & $\begin{array}{l}\mathrm{TS} \\
(\%)\end{array}$ \\
\hline WN alone & 7.7 & 0.60 & 1.2 & 0.38 & 0.01 & 710 & 321 \\
\hline KL-20\% WN & 7.5 & 0.69 & 3.6 & 0.69 & 0.09 & 214 & 107 \\
\hline HAL- $20 \% \mathrm{WN}$ & 7.5 & 0.68 & $\begin{array}{c}11.6 \\
(10.4-12.8)\end{array}$ & $\begin{array}{c}1.80 \\
(1.72-1.87)\end{array}$ & $\begin{array}{c}0.74 \\
(0.71-0.79)\end{array}$ & $\begin{array}{c}100 \\
(96.5-103.5)\end{array}$ & $\begin{array}{c}22 \\
(21.1-22.3)\end{array}$ \\
\hline Commercial & 9.0 & 0.60 & $\begin{array}{c}22.6 \\
(22.1-25.6)\end{array}$ & $\begin{array}{c}1.92 \\
(1.85-1.96)\end{array}$ & $\begin{array}{c}0.65 \\
(0.60-0.69)\end{array}$ & $\begin{array}{c}46 \\
(44.1-48.6)\end{array}$ & $\begin{array}{c}10 \\
(8.9-11.0)\end{array}$ \\
\hline
\end{tabular}

${ }^{*}$ WN: Waste newspaper, KL: Kraft lignin. The Values in parentheses were maximum and minimum values in the three specimens tested. 


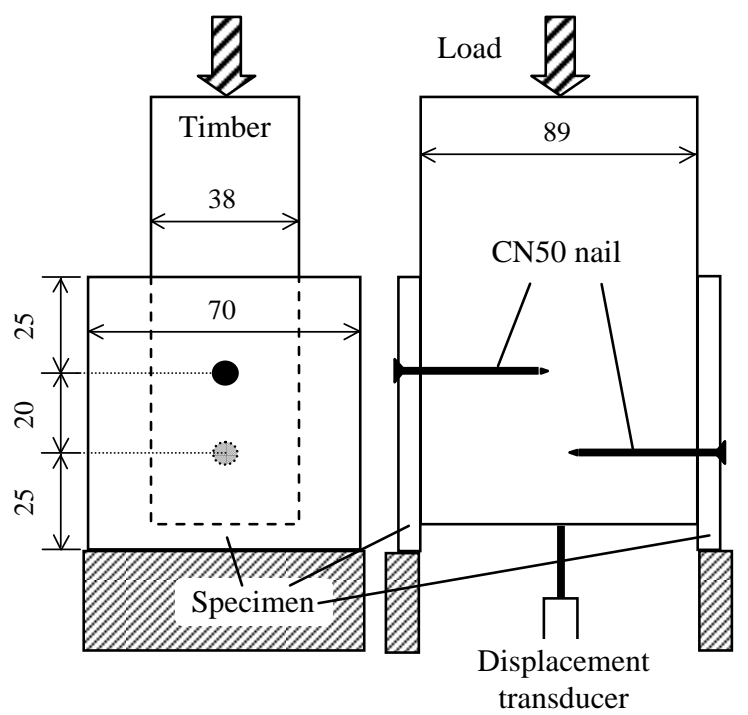




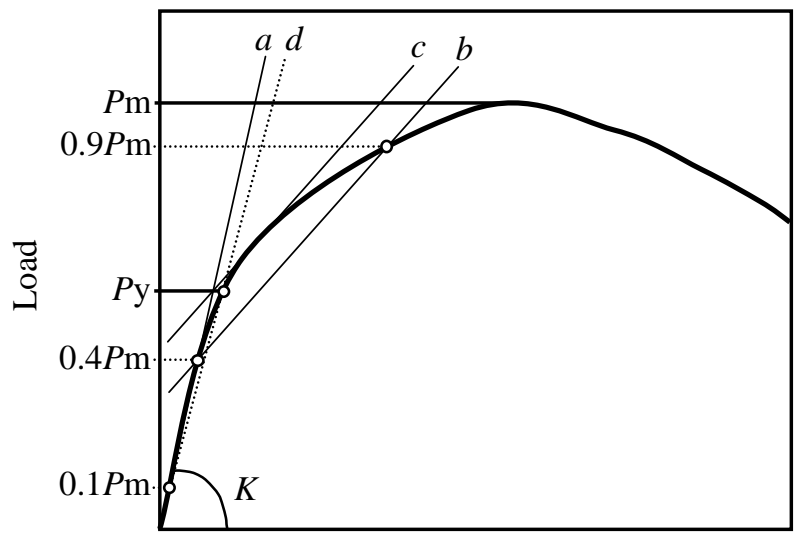

Deformation (rad) 


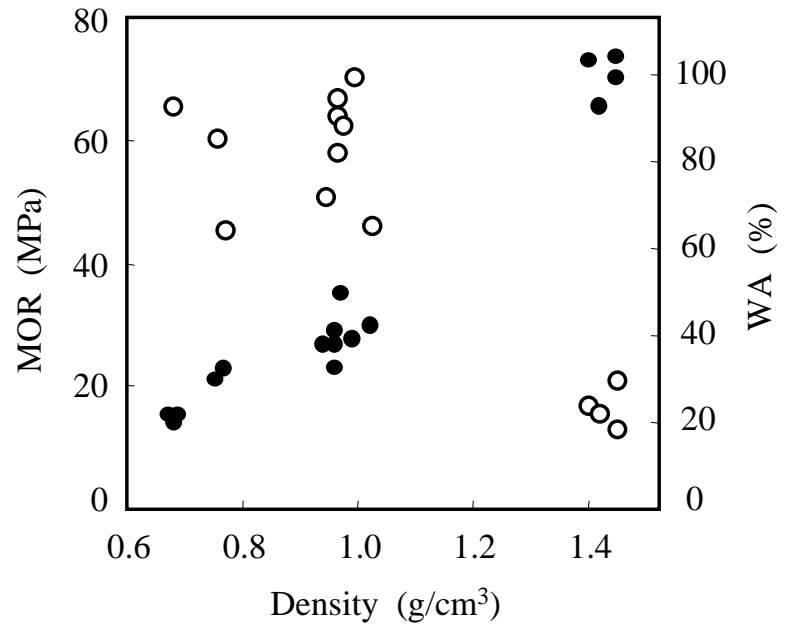



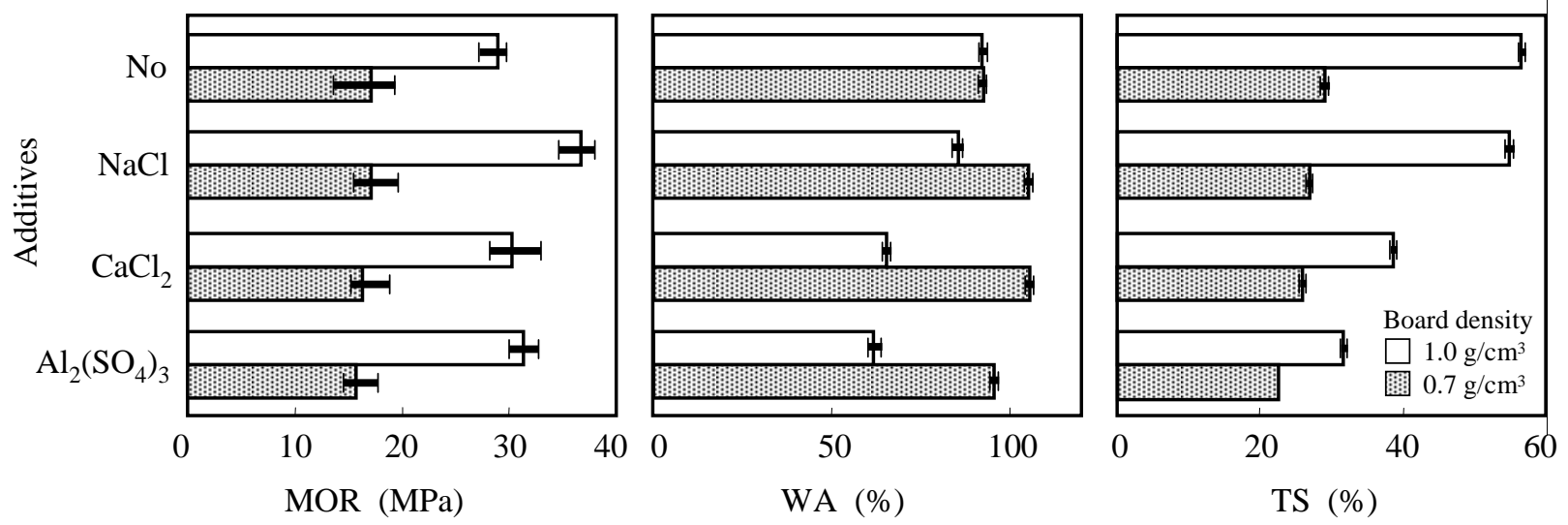

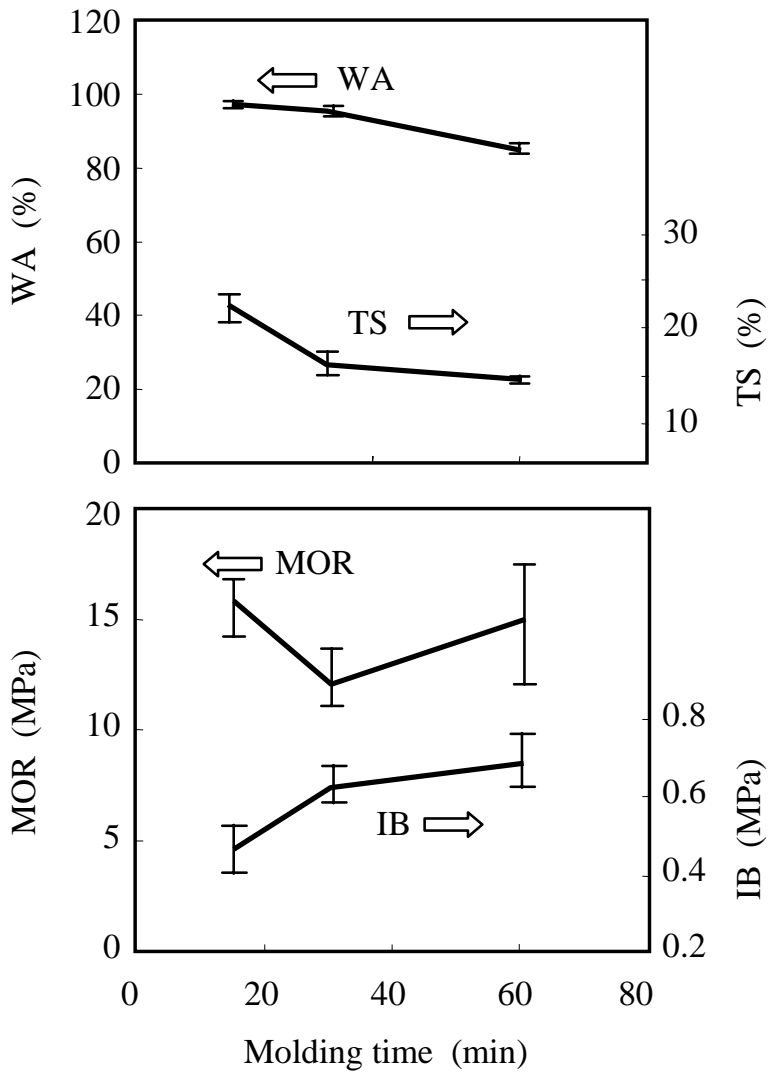


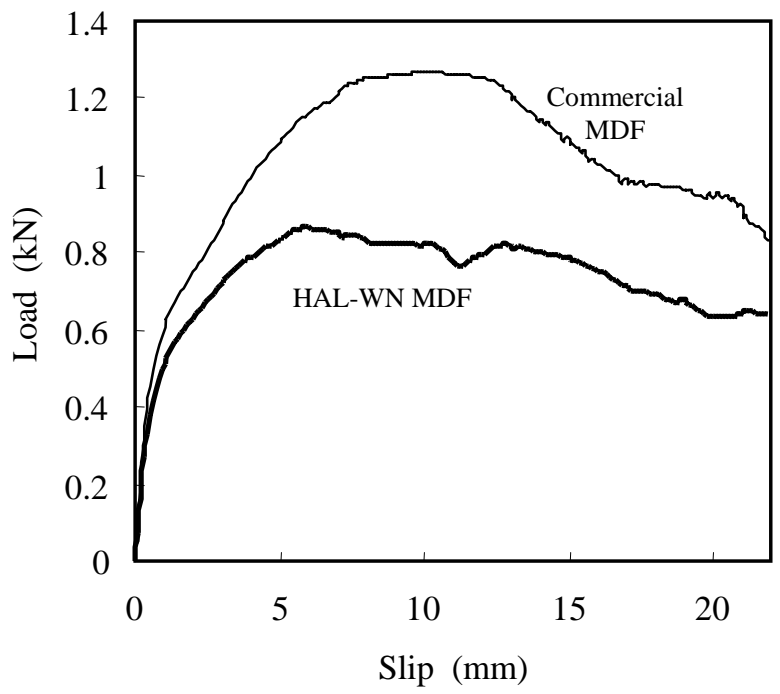




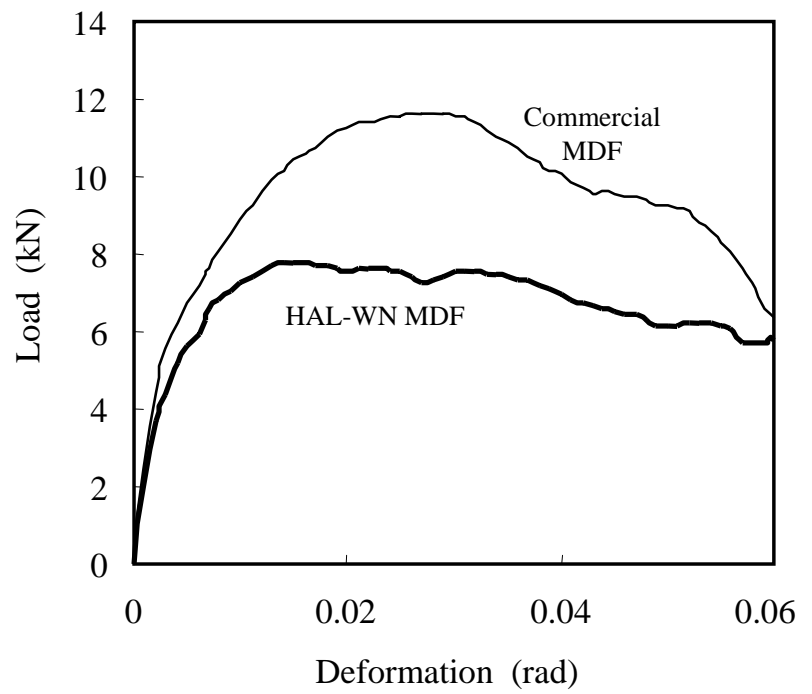

